\title{
AN EVALUATION OF STELLATE GANGLION BLOCK IN THE TREATMENT OF POST-TRAUMATIC DYSTROPHIC DISTURBANCES \\ IN THE UPPER EXTREMITY*
}

\author{
R. A. GondoN, B.SC., M.D., F.R.C.P.(C), F.F.A.R.C.S., AND \\ Shashi B. GOEL, M.B., B.S., F;R.C.P. (c)
}

IN 1864 Weir Mitchell published the classical description of a syndrome in which, after wounds of the extremities with nerve involvement, a persistent burning pain was the prime feature. Mitchell coined the word "Causalgia" to describe this syndrome. ${ }^{1}$

It has become apparent that there are variations in the circumstances surrounding the condition. Both the causative trauma and the clinical manifestations vary. In some, the painful part is hot and dry, in others cold and moist with sweat. In some, trophic disturbances of the skin (shiny taut skin with curved or pitted nails) is a prominent feature, while in others the skin appears essentially normal. Some are associated with oedema, others have none. In many there are severe trophic changes but little or no pain. The precipitating trauma may be severe or insignificant. Some are the result of localized infections or thrombophlebitis. In recent years the term sympathetic dystrophy has been generally accepted to describe these conditions. ${ }^{2}$

The mechanism of this disturbance and the cause of pain are not known. The variability in the circulation and the lack of correlation between the circulation and subjective pain cast doubt on theories which attribute the sympathetic dystrophies to local ischaemia or imbalance of the microcirculation. The most reasonable theory seems to be that causalgic pain is brought about by the stimulation of somatic sensory fibres by impulses in adjacent sympathetic efferents. ${ }^{3}$ In such a "conjunction" of sensory and sympathetic fibres the cut or crushed region thus serves as an artificial synapse. Such a situation could develop in the periphery as a result of local metabolic disturbances. This theory of fibre interaction fits the observed fact that relief is obtained by blocking the appropriate sympathetic nerves.

In our society most sympathetic dystrophies occur following industrial accidents causing trauma to the hand. These dystrophic disturbances constitute one of the greatest causes of disability in the injured industrial worker, and produce incapacity for months or years after anatomical healing of the injury is complete.

Immediate relief of the pain and discomfort is obtained by blocking the appropriate sympathetic nerves, and it has been observed that serial repetition of such blocks may lead to a cure or to a reduction of the disability. We have reviewed the records of 172 cases of post-traumatic dystrophy of the upper

From the Department of Anaesthesia, University of Toronto, and the Toronto General Hospital. 
extremity referred by the Workmen's Compensation Board of Ontario for treatment by local anaesthetic block of the stellate ganglion. Of these patients 159 were male and 13 were female. Of these cases, 170 were the result of industrial accidents, one was classed as occupational, being a vibration injury produced by the patient's occupation, and for one no causative factor was identified. The injuries included fractures, contusions, crush injuries, lacerations, amputations, burns, puncture wounds, and vibration injury.

It has long been appreciated that these dystrophic disturbances do not necessarily date from the moment of the accident. In the cases under review, only 13 or 7.6 per cent reported pain in the first week. In 60 or 35 per cent the pain appeared between the second and fourth week while in 82 or 47.9 per cent the interval between injury and onset was between one month and one year. Six or 3.5 per cent first experienced pain more than one year after the injury. In 10 cases the interval between injury and onset is not recorded (Table I).

\section{TABLE I}

Sympathetic Reflex Dystrophy-Interval FROM INJURY TO ONSET OF PAIN (161 CASES)

\begin{tabular}{lrr}
\hline \multicolumn{1}{c}{ Period } & \multicolumn{2}{c}{ Proportion } \\
\hline $1-7$ days & 13 & $8.0 \%$ \\
$2-4$ weeks & 60 & $37.2 \%$ \\
1 month to 1 year & 82 & $50.9 \%$ \\
Over 1 year & 6 & $3.1 \%$ \\
\hline
\end{tabular}

Pain was the one universal symptom in this group of patients. Only one patient of the 172 reviewed did not complain of pain. The other signs and symptoms which appeared in various combinations were swelling, stiffness, colour changes, hyperaesthesia, hyperhydrosis, trophic changes of skin and nails, sensitivity to cold, painful trigger points, areas of hypoaesthesia and phantom sensations (Table II). As far as we can determine there is no standard pattern for association of one of these signs or symptoms with another, nor have we been able to determine any relationship between the type of injury, the type of treatment, or the duration of the disturbance which could be related to the appearance of these symptoms.

We have endeavoured to assess the results of treatment of this group of reflex dystrophies by examining the subsequent records of the patients with reference to further treatment or discharge from the care of the Compensation Board. We have found it possible to examine the records of 165 patients in this way, and find that of this group, 37 were cured of their dystrophic complaint, 105 are classed as improved, and 23 were not improved (Table III). The number of stellate ganglion blocks varied from 2 to 10 , and the standard procedure was to block them twice weekly.

The interval between the onset of pain and the beginning of treatment by stellate ganglion block appeared to have little influence on the result if treatment was commenced within one year. Of those treated within the first month 88.7 per cent had a good result, while 85 per cent of those treated in the first 
TABLE II

Signs and Symptoms in 172 Cases of Post-Traumatic Dystrophy OF THE UPPER EXTREMITY

\section{SIGNS \& SYMPTOMS}

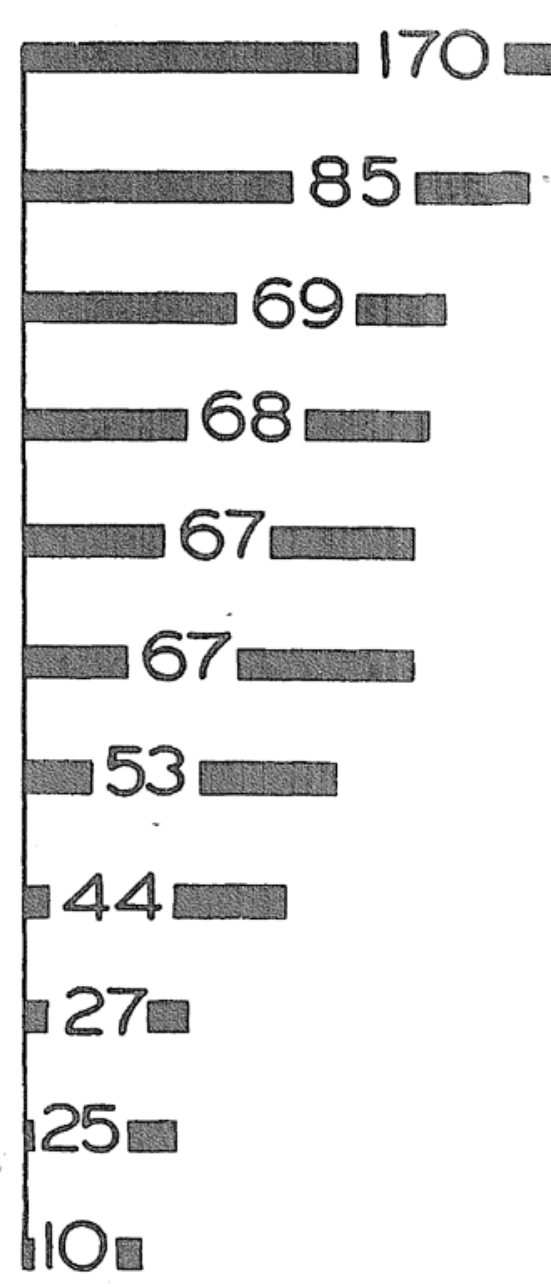

Pain

Swelling

Stiffness

Discolouration

Hyperaesthesia

Sweating

Skin changes

Sensitivity to cold

Numbness

Trigger points

Phantom limb

TABLE III

Sympathetic Reflex Dystrophy

Stellate Ganglion Blocks (165 Results)

\begin{tabular}{lr}
\hline \hline Cured & 37 \\
Improved & 105 \\
Unchanged. & 23 \\
\hline
\end{tabular}

year following the development of symptoms were improved or cured. Those treated within the first week of the development of symptoms were all improved, while only 42.8 per cent of those treated more than one year after the development of symptoms were improved. However, in the early and the late cases the series is too small to be statistically significant.

It should be pointed out that adequate functional improvement in these hands cannot be produced by stellate ganglion block alone except in the period immediately following injury. In the more chronic disabilities, sympathetic block must be combined with intelligent and persistent physiotherapy aimed at improvement of function. To assess the influence of the sympathetic block therapy properly in the cases under discussion, it must be emphasized that these patients 
had been receiving physiotherapy and other forms of treatment for periods varying from weeks to over one year before they were referred for block therapy, and that in almost every case the patient was referred because his situation was not improving with physiotherapy alone. Return of optimal function, within the limits of the anatomical disability imposed by the injury, depends on a rational combination of sympathetic block and physiotherapy aimed at restoration of function.

The following case histories are illustrative of the results which may be obtained by this form of treatment.

Mr. C. H. This man suffered multiple lacerations of the right hand in a circular saw two months prior to commencement of treatment. At the time he had primary suture of the flexor tendons and digital nerves. He was referred for treatment with marked dystrophic changes in the skin and nails, fusiform swelling of the fingers, hyperhydrosis but no complaint of pain. He was unable to flex his fingers to make a fist. Following five stellate ganglion blocks associated with physiotherapy in the intervals, the hand was dry, the skin normal in appearance, he was able to flex his fingers, and returned to work.

$M r . M$. This patient had suffered fracture of the metacarpals of the right hand and a transverse laceration of the proximal phalanx of the middle finger one month before treatment. On beginning treatment the hand was markedly swollen with thin, shiny, atrophic skin. One week later after three stellate blocks the swelling of the hand had disappeared, and the patient was able to make a reasonable fist.

Mr. J. V. This patient suffered loss of portions of the tips of the third, fourth, and fifth fingers three months prior to treatment. The defects had been grafted, the skin being taken from the dorsum of the fingers. There was hyperaesthesia of the grafted areas of the tips of the fingers, the hand was sweaty, and he was completely incapacitated. Ten days later, after three stellate ganglion blocks, the hand was dry, hyperaesthesia had disappeared, and he was able to use the hand freely.

\section{SUMMARY}

Post-traumatic sympathetic dystrophies occur frequently following trauma to the hand. The precipitating trauma may be severe or insignificant. These dystrophic disturbances constitute one of the greatest causes of disability in the injured industrial worker. Immediate relief of the pain and discomfort is obtained by blocking the appropriate sympathetic nerves, and it has been observed that serial repetition of such blocks may lead to a cure or to a reduction of disability. We have reviewed the records of 172 patients suffering from disability of this kind who were treated by serial stellate ganglion blocks associated with a programme of physiotherapy. Of these, the long-term results could be assessed in 165, of whom 37 were cured, 105 improved, and only 23 were unchanged. There appeared to be no relationship between the result obtained and the duration of the disability prior to institution of treatment. Since these patients had been receiving physiotherapy and other forms of treatment for periods varying from weeks to over one year before they were referred for block therapy, it must be concluded that sympathetic block has played an important rolle in the restoration of function in the cases reported. 


\section{RÉSUMÉ}

Les dystrophies sympathiques post-traumatiques sont souvent observées à la suite d'un traumatisme de la main. Le facteur déclenchant peut être sévère ou simplement insignifiant. Ces troubles dystrophiques constituent une des plus grandes causes d'incapacité chez le travailleur industrial traumatisé. Le soulagement immédiat de la douleur est obtenu en bloquant le nerf sympathique approprié, et il a été observé que la répétition en série de tels blocs peut conduire à la guérison, ou à la diminution de l'incapacité. Nous avons revu les dossiers de 172 malades souffrant de ce genre d'incapacité et qui ont été soumis à une série de blocs du ganglion étoilé associé à un programme de physiothérapie. De ces dossiers, les résultats à long terme peuvent être évalués dans 165 cas: 37 ont été guéris, 105 améliorés et 23 seulement n'ont éprouvé aucune amélioration. Fait à noter, on n'a pu établir aucune relation entre le résultat obtenu et la durée de l'incapacité avant l'institution du traitement. Presque tous ces malades avaient été soumis à la physiothérapie et autres formes de traitement dans des laps de temps variant de quelques semaines à une année et plus avant d'être soumis au blocage sympathique; on doit donc conclure que le bloc sympathique a joué un rôle important dans le rétablissement de la fonction du membre dans les cas qui ont été rapportés.

\section{REFERENCES}

1. Mitchell, S. W.; Mopezouse, G. R.; \& KNEN, W. W. Ciunshot Wounds and Other Injuries of Nerves. Philadelphia: ]. B. Lippincott Co. (1864).

2. Druckers, W. R.; Hubay, C. A.; HoldeN, W. D.; \& ButsovnIC, J. A. Pathogenesis of Post-traumatic Sympathetic Dystrophy. Amer. J. Surg. 97: 454-465 (1959).

3. Doupr, J.; Cullen, C. A.; \& CRANCE, C. Q. Post-traumatic Pain and the Causalgic Syndrome. J. Neurol. Neurosurg. Psychiat. 7: 33-48 (1944). 